\title{
Creation in shifting to digital
}

\author{
Patricia A. Young ${ }^{1}$ \\ Published online: 28 January 2021 \\ (c) Association for Educational Communications and Technology 2021
}

The importance of learning and mastering languages is of great concern to many who value globalization, multilingualism and technology. Computer-Assisted Language Learning or CALL finds its roots in applied linguistics and computer science. According to Beatty (2013) "CALL Programs are little more than a tool mimicking a textbook, a learner's peer or a teacher (p. 2)." This statement is arguable, but the truth is that computers have been used for language learning since the 1960s (Warschauer \& Healey, 1998).

Constructing a CALL system seems to be a daunting task that requires a mastery of language, literacy and computer science expertise. In Liu et al. (2019), the researchers embark upon the task of building Jastudy a CALL program that helps Chinese speaking second language learners master Japanese functional expressions. Liu et al. (2019) propose that a large number of Chinese characters are commonly used in both Japanese and Chinese. However, Chinese-speaking learners of Japanese find it challenging to learn Japanese functional expressions. To address this problem, the authors developed Jastudy.

Building technologies to meet the language and literacy needs of people is one way to satisfy the needs of communities. Creating is part of the shifting to digital revolution.

This section of the special issue offers responses of two scholars who critique and examine Lui et al.'s (2019) study. Fulton, Hoffman and Paek approach the article from a research perspective and view the CALL system from three emerging themes related to "shifting to digital": datafication, convergence and personalized learning. Shortt approaches the paper from a cultural perspective by initially inserting himself in the study and then analyzing the cultural context that could have enhanced the paper.

\section{References}

Beatty, K. (2013). Teaching \& researching: Computer-assisted language learning. London: Routledge.

Liu, J., Shindo, H., \& Matsumoto, Y. (2019). Development of a computer-assisted Japanese functional expression learning system for Chinese-speaking learners. Educational Technology Research and Development, 67, 1307-1331. https://doi.org/10.1007/s11423-019-09669-0.

Warschauer, M., \& Healey, D. (1998). Computers and language learning: An overview. Language teaching, 31(2), 57-71.

Patricia A. Young

pyoung@umbc.edu

1 University of Maryland Baltimore County, 1000 Hilltop Circle, Baltimore, MD 21250, USA 
Publisher's Note Springer Nature remains neutral with regard to jurisdictional claims in published maps and institutional affiliations.

Patricia A. Young is an educational technologist, professor and software developer. She is Program Director of Elementary Education and Associate Professor in the Department of Education at the University of Maryland Baltimore County. Her research examines culture and the design of information and communication technologies and the history of educational technologies designed by and for African Americans. 